
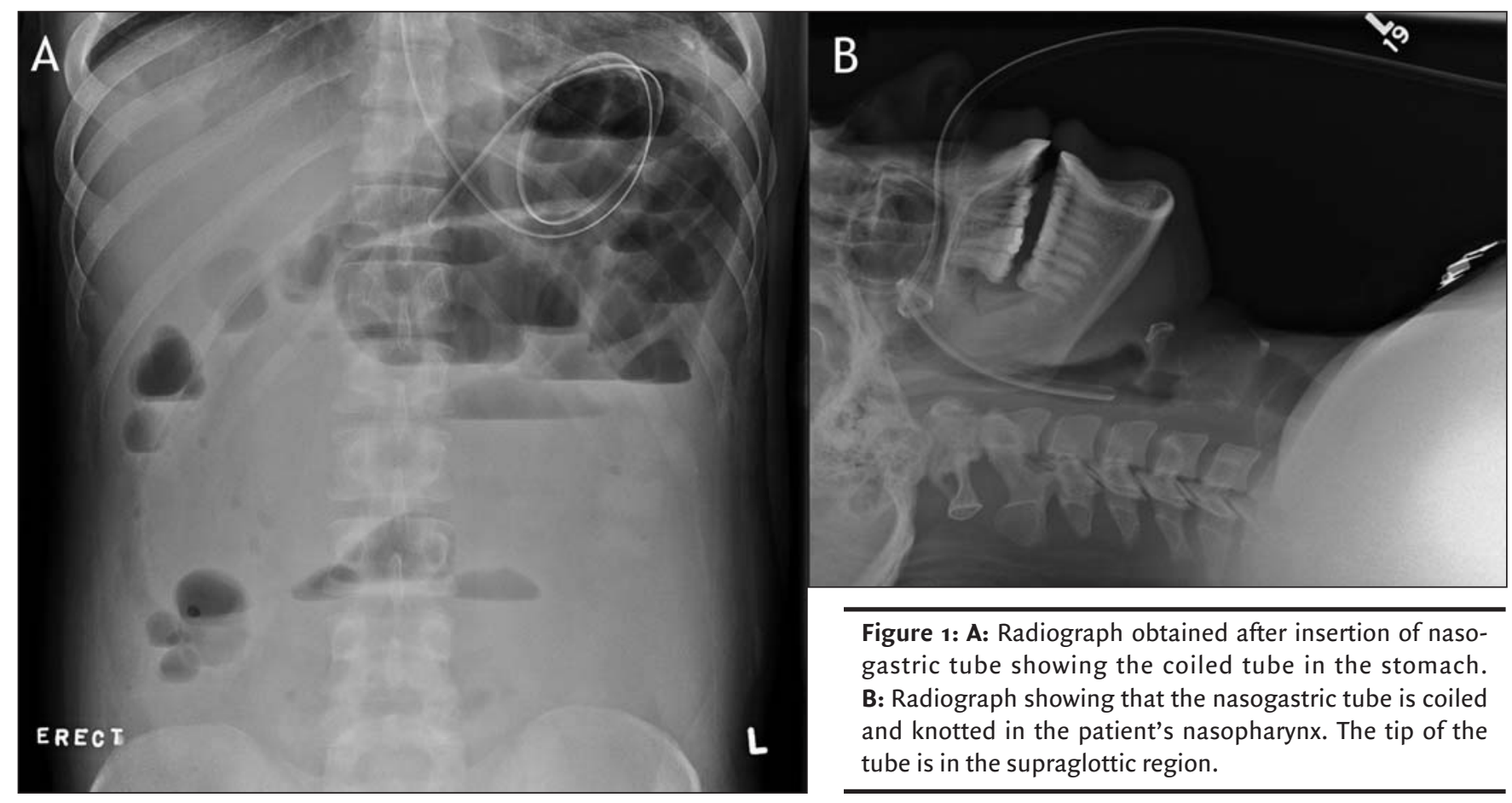

Figure 1: A: Radiograph obtained after insertion of nasogastric tube showing the coiled tube in the stomach. B: Radiograph showing that the nasogastric tube is coiled and knotted in the patient's nasopharynx. The tip of the tube is in the supraglottic region.

\title{
A painful and knotted nasogastric tube
}

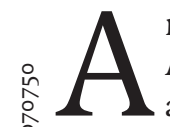
nasogastric tube was inserted in a 35 -year-old man before a surgical procedure. After the operation when the tube was being removed, the patient experienced an excruciating pain in his nasopharynx. The tube could not be advanced out递 ward or inward. A radiograph showed a knotted nasogastric tube in the patient's nasopharynx (Figure I). The tube was eventually removed through the oral cavity by use of a McGill forceps. Upon further review of the radiograph, we saw that the tube was coiled in the patient's stomach, which could have led to it becoming knotted when it was being pulled out.
CMAJ invites contributions to Interesting images, a new column with a very brief but clear description of the case, the images and the main teaching point. Submit manuscripts online at http://mc.manuscriptcentral.com/cmaj.
Shruti Niranjan Tapiawala MD Dawood Al Riyami MD

Department of Medicine and Nephrology

Edward Cole MD

Department of Renal Transplantation University Health Network

Toronto, Ont. 